\title{
Article \\ Intra-Articular Administration of Cramp into Mouse Knee Joint Exacerbates Experimental Osteoarthritis Progression
}

\author{
Moon-Chang Choi ${ }^{1}$, Jiwon Jo ${ }^{1}$, Myeongjin Lee ${ }^{1}$, Jonggwan Park ${ }^{2}$ and Yoonkyung Park ${ }^{1, *}$ \\ 1 Department of Biomedical Science, Chosun University, Gwangju 61452, Korea; \\ choist777@chosun.ac.kr (M.-C.C.); ehklw155@chosun.ac.kr (J.J.); ksf9696@chosun.ac.kr (M.L.) \\ 2 Department of Bioinformatics, Kongju National University, Kongju 38065, Korea; jgpark@kongju.ac.kr \\ * Correspondence: y_k_park@chosun.ac.kr
}

check for updates

Citation: Choi, M.-C.; Jo, J.; Lee, M.; Park, J.; Park, Y. Intra-Articular Administration of Cramp into Mouse Knee Joint Exacerbates Experimental Osteoarthritis Progression. Int. J. Mol. Sci. 2021, 22, 3429. https://doi.org/ $10.3390 /$ ijms 22073429

Academic Editor: Elena Bonanno

Received: 2 March 2021

Accepted: 24 March 2021

Published: 26 March 2021

Publisher's Note: MDPI stays neutral with regard to jurisdictional claims in published maps and institutional affiliations.

Copyright: (c) 2021 by the authors. Licensee MDPI, Basel, Switzerland. This article is an open access article distributed under the terms and conditions of the Creative Commons Attribution (CC BY) license (https:/ / creativecommons.org/licenses/by/ $4.0 /)$.

\begin{abstract}
Osteoarthritis (OA) is the most common type of arthritis and is associated with wear and tear, aging, and inflammation. Previous studies revealed that several antimicrobial peptides are upregulated in the knee synovium of patients with OA or rheumatoid arthritis. Here, we investigated the functional effects of cathelicidin-related antimicrobial peptide (Cramp) on OA pathogenesis. We found that Cramp is highly induced by IL-1 $\beta$ via the NF- $k B$ signaling pathway in mouse primary chondrocytes. Elevated Cramp was also detected in the cartilage and synovium of mice suffering from OA cartilage destruction. The treatment of chondrocytes with Cramp stimulated the expression of catabolic factors, and the knockdown of Cramp by small interfering RNA reduced chondrocyte catabolism mediated by IL-1 $\beta$. Moreover, intra-articular injection of Cramp into mouse knee joints at a low dose accelerated traumatic OA progression. At high doses, Cramp affected meniscal ossification and tears, leading to cartilage degeneration. These findings demonstrate that Cramp is associated with OA pathophysiology.
\end{abstract}

Keywords: osteoarthritis; cramp; cathelicidin; cartilage degeneration; meniscus ossification

\section{Introduction}

Osteoarthritis (OA) is a joint disorder that affects most of the joint components, such as by causing articular cartilage degeneration, synovial inflammation, subchondral bone sclerosis, osteophyte formation and/or meniscal tear [1]. This degenerative joint disease is caused by overuse and overload of the joints together with joint inflammation, and leads to pain and disability mainly in the aging and obese populations [2]. Acute or degenerative meniscal lesions that decrease knee joint stability are also associated with disease development in patients with $\mathrm{OA}$, including relatively young individuals [3-5]. OA treatment is currently limited to pain control without licensed disease-modifying OA drugs. Defining OA-associated factors may provide biomarkers and therapeutic targets.

Cartilage homeostasis is maintained by a balance between chondrocyte anabolism and catabolism. Chondrocytes, the only cell type present in cartilage, normally produce a large amount of anabolic extracellular matrix (ECM) proteins, such as Col2a1 and aggrecan, to tolerate shearing forces and absorb shock [6]. However, in OA disease, prolonged mechanical stress and synovial inflammation promote chondrocyte catabolism, leading to ECM degradation and breakdown in the cartilage [7-9]. The infrapatellar fat pad also contributes to OA pathogenesis by producing pro-inflammatory mediators [10]. Mechanistically, chondrocytes stimulated by pro-inflammatory cytokines or ECM degradation products from OA lesions express high levels of catabolic factors such as matrix metalloproteinases (MMPs) and aggrecanases (ADAMTSs) [11-13], which degrade the cartilage matrix. The induction of these catabolic genes occurs via several signaling pathways, including NF- $\kappa B$ transcription factor and associated $\mathrm{I} \kappa \mathrm{B} \zeta[14,15]$. The genetic ablation of these genes in chondrocytes can protect against OA development $[15,16]$. Hence, identifying factors that regulate catabolic pathways can provide potential therapeutic targets for OA. 
The meniscus plays integral roles in preserving joint health and preventing OA lesions. Due to its shock absorption capability, it is well-accepted that pathologic changes in menisci due to injury predispose individuals to OA development $[17,18]$, and thus meniscus damage is considered to be a risk factor for OA. Although the mouse knee joint normally shows small areas of ossification in the anterior meniscal horn [19], either traumatic or spontaneous OA leads to severe ossification of the mouse meniscus [20]. In other animals, such as guinea pigs, dogs, and pigs, meniscus ossification is also closely associated with OA cartilage damage [21-25]. However, compared with the understanding of OA pathogenesis related to cartilage degeneration or synovial inflammation, the factors associated with $\mathrm{OA}$ meniscal damage are poorly understood.

Antimicrobial peptides (AMPs), also known as host defense peptides, are components of innate immunity and play critical roles in protecting against bacterial, viral, and fungal infections [26]. Two major AMPs in mammals are cathelicidins and defensins, which have broad-range antimicrobial activities $[27,28]$. The only cathelicidin protein identified to date in humans is LL-37. This short peptide is derived from the precursor protein hCAP18 via proteolytic cleavage [29]. Cathelicidin-related antimicrobial peptide (Cramp), the rodent homologue of LL-37, also shows potent antibiotic activity and is expressed in many cell types such as neutrophils [30,31], adipocytes [32], macrophages [33], and epithelial cells [34]. In addition to their roles in infectious diseases, cathelicidins have pleiotropic effects in noninfectious diseases such as acute thrombosis [30], atherosclerosis [31], carcinogenesis [35], kidney injury [36], cardiac dysfunctions [37,38], and liver injury [39] by exerting either disease-causative or protective roles.

Interestingly, several AMPs, including LL-37 and human beta-defensin 3 (HBD-3), have been implicated in the pathogenesis of arthritic diseases. In fact, it has long been recognized that LL-37 is elevated in the synovial membrane of patients with OA and rheumatoid arthritis (RA) [40]. More recent reports supported the up-regulation of cathelicidins in the RA synovium [41-43]. However, whether cathelicidins function in the development of OA remains unknown. Therefore, the objective of this study was to investigate whether Cramp is involved in OA pathogenesis.

\section{Results}

\subsection{Cramp Is Induced by Pro-Inflammatory Cytokines via NF- $\kappa B$ Pathway in Chondrocytes}

Soluble mediators, such as pro-inflammatory IL- $1 \beta$ and TNF- $\alpha$, secreted from damaged joints simulate catabolic gene expression in cultured chondrocytes and thus transform them into ECM-catabolizing cells [11]. We first analyzed whether Cramp expression is altered by IL- $1 \beta$ in mouse primary chondrocytes. The results showed that Cramp mRNA was rapidly and strongly induced by IL-1 $\beta$ in a time-dependent manner (Figure $1 \mathrm{~A}$ ). TNF- $\alpha$ also significantly increased the mRNA level of Cramp, but to a lesser extent compared to IL-1 $\beta$ (Figure 1B).

NF- $\mathrm{KB}$ induces many genes associated with OA cartilage degeneration [14]. To examine whether IL- $1 \beta$-induced expression of Cramp is mediated by NF- $\mathrm{KB}$, we treated chondrocytes with SC514, an IKK $\beta$ inhibitor [44], and observed significant suppression of Cramp induction (Figure 1C). This result suggests that pro-inflammatory IL- $1 \beta$ induces Cramp expression in an NF- $\mathrm{kB}$-dependent manner during chondrocyte catabolism.

\subsection{Cramp Expression Is Elevated in Cartilage and Synovium of Experimental $O A$}

We next investigated whether Cramp is indeed activated in joint components during OA development. Experimental OA was induced by subjecting mice to destabilization of the medial meniscus (DMM) surgery, which leads to ECM degradation and synovial inflammation (Figure 2A). Cramp levels in knee joints from sham-operated or DMMoperated mice were determined by immunohistochemistry (IHC) staining (Figure 2B,C). Compared to sham-operated joints, DMM-operated joints exhibited strong expression of Cramp in both the articular cartilage and synovium. Cramp levels in the meniscus 
were comparable between sham and DMM. This in vivo finding suggests that Cramp is activated in the cartilage and synovium during experimental OA progression.

A

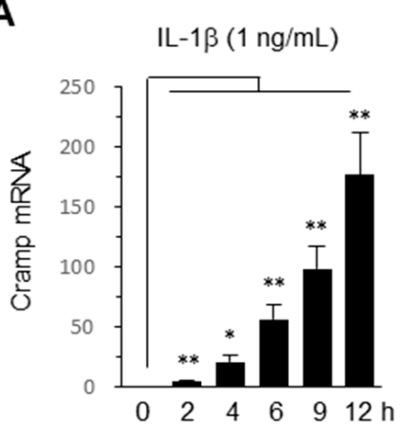

B

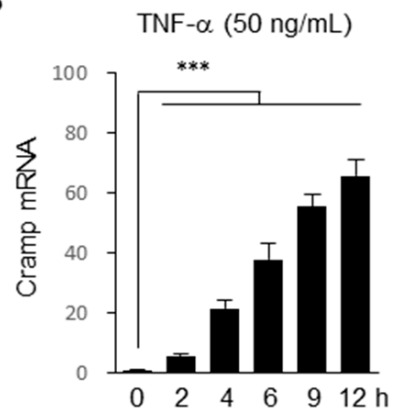

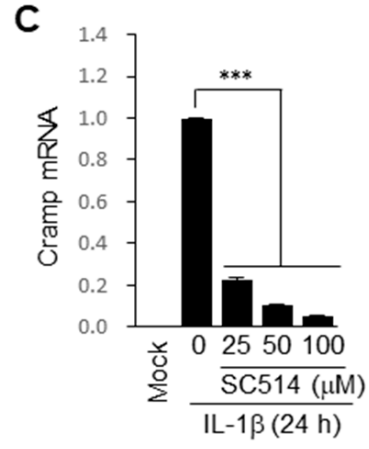

Figure 1. Cathelicidin-related antimicrobial peptide (Cramp) expression is up-regulated via NF$\mathrm{KB}$ signaling pathway in pro-inflammatory cytokine-treated chondrocytes. (A) Mouse primary chondrocytes were treated with IL- $1 \beta$ for the indicated concentrations and times. The mRNA level of Cramp was determined by quantitative PCR $(n=4)$. Values are the means \pm SEM. ${ }^{*} p<0.05$, ** $p<0.01$ versus untreated $0 \mathrm{~h}$. (B) Cramp mRNA was examined in chondrocytes treated with TNF- $\alpha$ for the indicated times $(n=4)$. (C) Chondrocytes pre-treated with SC514 for $1 \mathrm{~h}$ were treated with IL-1 $\beta$ for $24 \mathrm{~h}$. The mRNA level of Cramp was determined by qPCR $(n=5)$. Values are the means \pm SEM. ${ }^{* * *} p<0.001$.

A

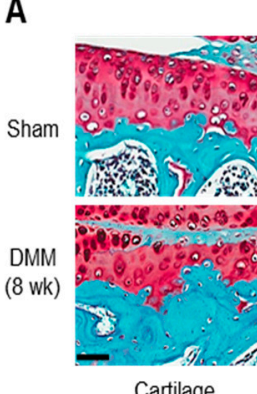

Safranin-0

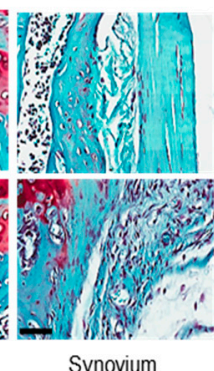

B

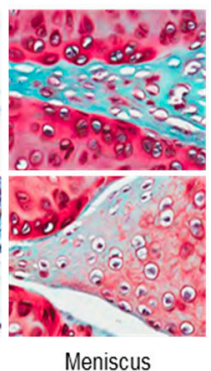

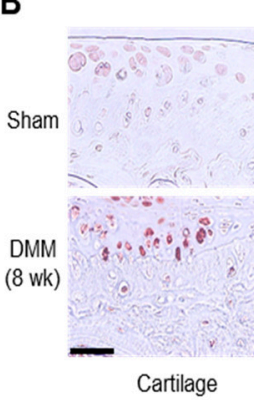

IHC (Cramp)

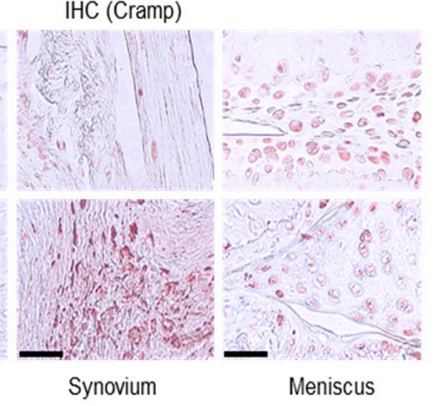

C

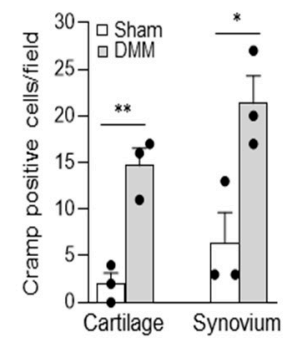

Figure 2. Cramp is up-regulated in cartilage and synovium during experimental osteoarthritis (OA). (A) Safranin-O staining of mouse cartilage, synovium and meniscus harvested at 8 weeks after destabilization of the medial meniscus (DMM) surgery. (B,C) Immunohistochemical staining (IHC) for Cramp in cartilage, synovium and meniscus. Bars $=50 \mu \mathrm{m}$. Values are the means \pm SEM. $n=3$ for each group. ${ }^{*} p<0.05,{ }^{* *} p<0.01$ versus sham.

\subsection{Cramp Increases Mmp3 and Mmp13 Expression in Chondrocytes}

The up-regulation of Cramp in OA chondrocytes led us to investigate whether Cramp plays a role in chondrocyte catabolism. A recent report showed that mouse Cramp and human LL-37 effectively worked on platelet activation at $>20$ and $>5 \mu \mathrm{M}$, respectively [30]. We therefore treated chondrocytes for $24 \mathrm{~h}$ with cathelicidins at $40 \mu \mathrm{M}$ Cramp or $10 \mu \mathrm{M}$ LL-37 and examined catabolic factor expression. Two types of synthetic AMPs, HP (2-20) and HP-MA, which exert potent antimicrobial activities [45,46], were used as control peptides. Compared to mock or control HP (2-20) peptide-treated groups, Cramp-treated chondrocytes showed higher expression of Mmp3 and Mmp13 (Figure 3A). LL-37 potently induced Mmp3 and Mmp13 (Figure 3B). Considering the crucial role of Mmp13 in OA matrix degradation [47], the increase in Mmp13 by Cramp suggested that Cramp might be associated with OA development. 
A

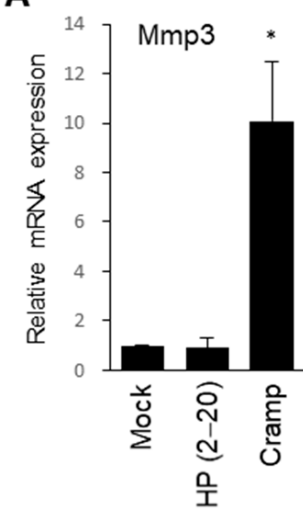

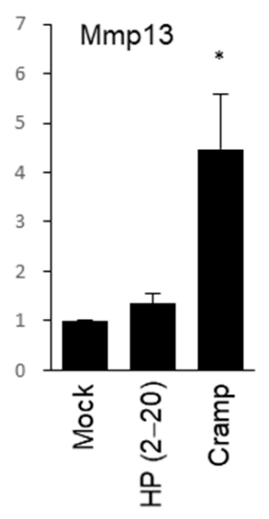

B

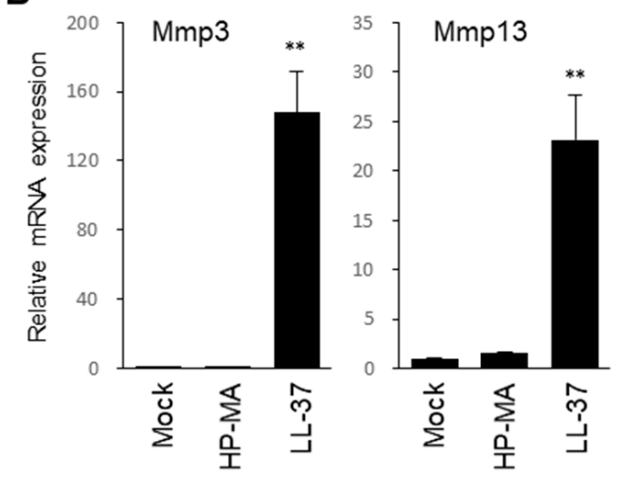

Figure 3. Treatment of Cramp or human LL-37 increases Mmp3 and Mmp13 expressions. (A) Mouse primary chondrocytes were treated with mock, control HP (2-20) peptide $(40 \mu \mathrm{M})$, or Cramp peptide $(40 \mu \mathrm{M})$ for $24 \mathrm{~h}$. mRNA levels of Mmp3 and Mmp13 were determined by qPCR $(n=3)$. (B) Chondrocytes were treated with mock, control HP-MA peptide $(10 \mu \mathrm{M})$, or LL-37 peptide $(10 \mu \mathrm{M})$ for $24 \mathrm{~h}$ $(n=3)$. Values are the means \pm SEM. ${ }^{*} p<0.05,{ }^{* *} p<0.01$ versus mock.

\section{4. siRNA-Mediated Knockdown of Cramp Reduces IL-1 $\beta$-Induced Catabolic Gene Expression}

To validate the function of Cramp in regulating matrix-degrading enzymes, we transiently inactivated Cramp by small interfering RNA (siRNA) knockdown (KD) in chondrocytes, and examined IL- $1 \beta$-induced catabolic factor expression. As shown in Figure 4A (left), the expression of Mmp3, Mmp13, and Adamts5 induced by IL-1 $\beta$ was decreased by Cramp KD. We also found that the reductions in anabolic aggrecan and Sox 9 by IL- $1 \beta$ were partially restored by Cramp KD (Figure $4 \mathrm{~A}$, right). Western blot analysis confirmed the reduction in Mmp3/13 and partial restoration of Sox9 in Cramp KD chondrocytes (Figure 4B). Collectively, these in vitro results indicate that Cramp is required for the proper activation of chondrocyte catabolism.

A

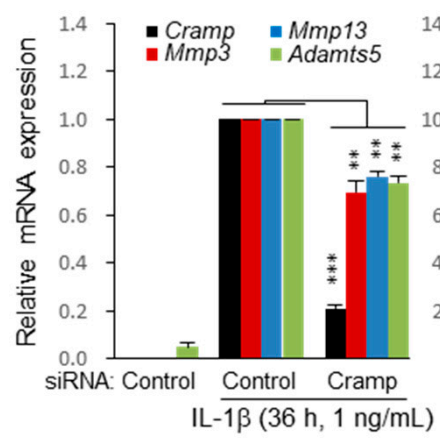

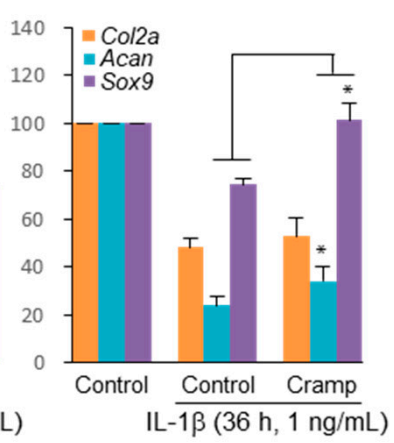

B

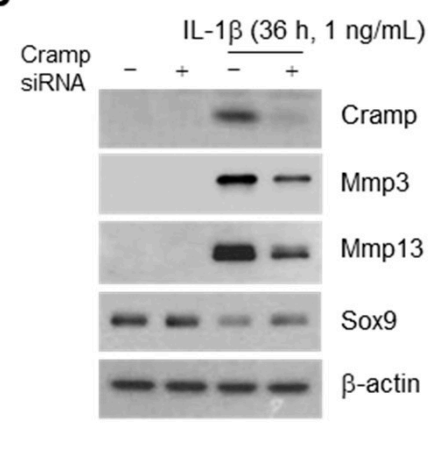

Figure 4. Small interfering RNA (siRNA) knockdown (KD) of Cramp attenuates catabolic factor expression induced by IL-1 $\beta$. Chondrocytes transfected with control or Cramp siRNA were treated with IL-1 $\beta$ for $36 \mathrm{~h}$. (A) mRNA levels of catabolic factors (left) and anabolic factors (right) were determined by qPCR $(n=4)$. Values are the means \pm SEM. ${ }^{*} p<0.05,{ }^{* *} p<0.01,{ }^{* * *} p<0.001$. (B) Cellular Cramp, Sox 9 , and $\beta$-actin and extracellular Mmp3 and Mmp13 were determined by Western blotting. Data from one representative experiment of two independent experiments are shown.

\subsection{Cramp Exacerbates the Progression of Experimental OA}

The functional role of Cramp was further investigated in vivo following the intraarticular (IA) injection of Cramp. We first determined which joint components are targets affected by secreted Cramp. The degree of Cramp internalization into the joint components was monitored at $24 \mathrm{~h}$ after IA injection of increasing concentrations of Cramp. As shown 
in Figure 5A, when a relatively low dose of Cramp $(10 \mu \mathrm{L}$ of $0.1 \mathrm{mM})$ was IA-injected, Cramp was enriched in the synovial membrane. Higher concentrations of Cramp (10 $\mu \mathrm{L}$ of 1-10 mM) led to a dose-dependent internalization of Cramp with the cartilage and meniscus as well as the synovium. This finding suggests that Cramp might play a role in OA by associating with the cartilage, synovium, and meniscus.

A

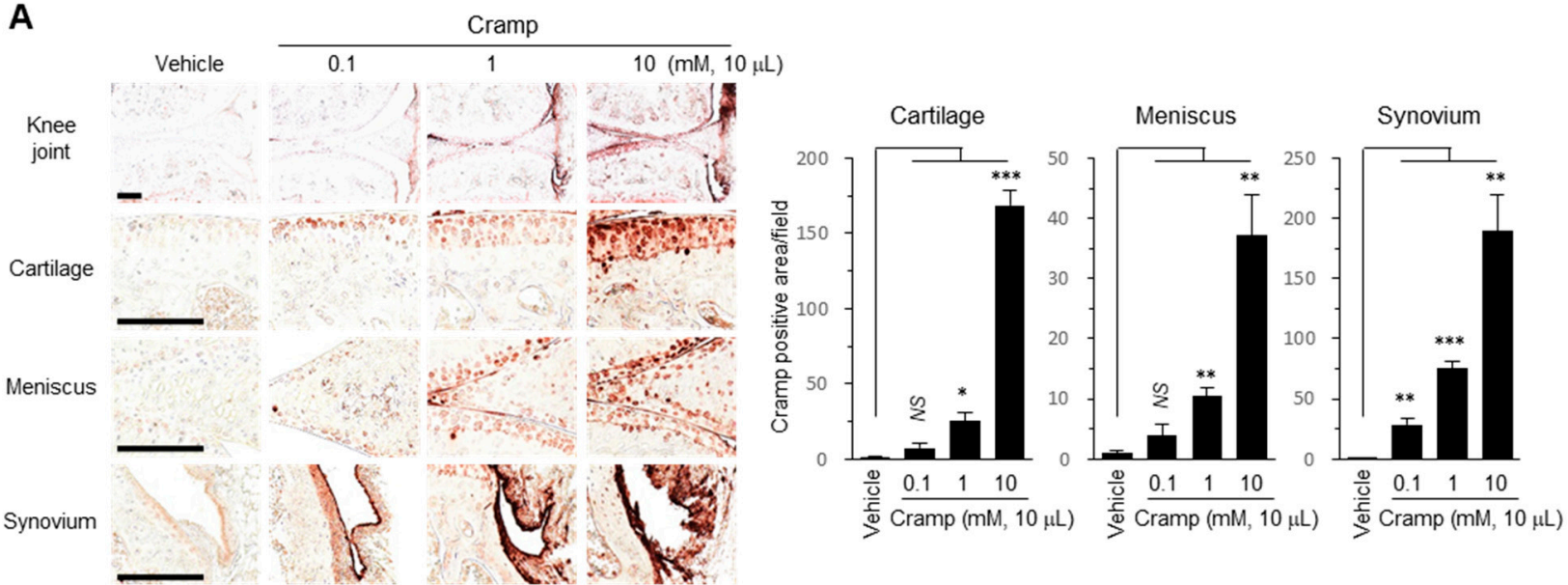

B
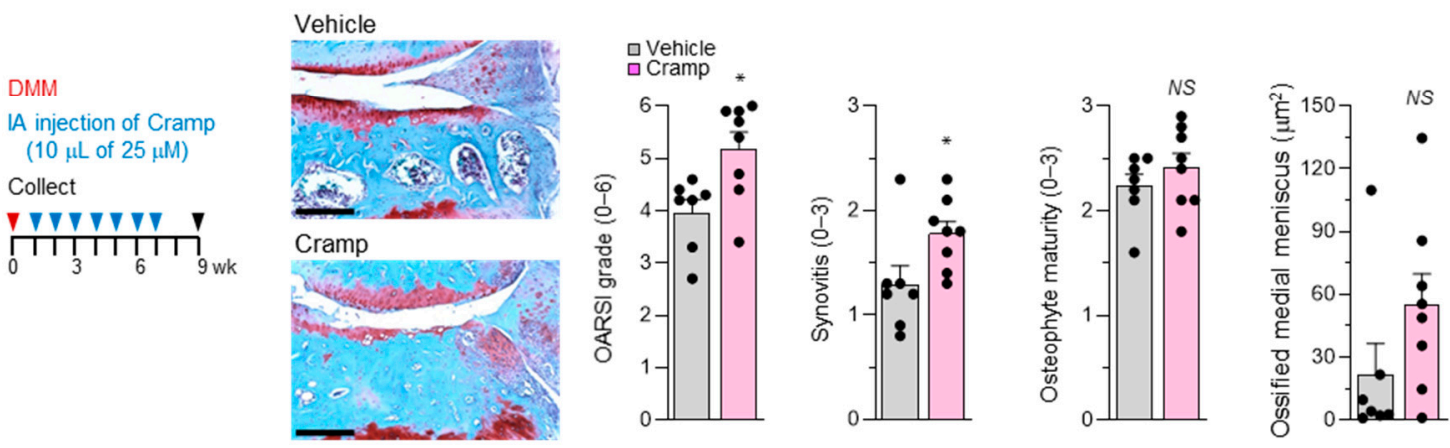

Figure 5. Cramp treatment into mouse knee joint by intra-articular (IA) injection promotes traumatic OA progression. (A) IHC staining of Cramp in mouse knee joints treated with indicated concentrations of Cramp for $24 \mathrm{~h}$. Bars $=200 \mu \mathrm{m}$. Values are the means \pm SEM. $n=3$ for each group. ${ }^{*} p<0.05,{ }^{* *} p<0.01,{ }^{* * *} p<0.001$ versus vehicle; $N S$, not significant. (B) 12-week-old male mice were subjected to DMM surgery, and treated with either vehicle $(n=7)$ or Cramp $(n=8)$ for the indicated periods and concentrations. Safranin-O staining, Osteoarthritis Research Society International (OARSI) grade, synovial inflammation, osteophyte maturity, and meniscus ossification are shown. Values are the means \pm SEM. ${ }^{*} p<0.05$ versus vehicle-treated group. Bars $=200 \mu \mathrm{m}$.

To evaluate the pathological changes caused by Cramp in OA, we repeatedly treated mice with a low dose of Cramp under experimental OA conditions. As shown in Figure 5B, 12-week-old male mice were subjected to DMM surgery. At 1 week after DMM, the mice were first treated with either vehicle or Cramp $(10 \mu \mathrm{L}$ of $25 \mu \mathrm{M}$, approximately $1 \mu \mathrm{g})$ by IA injection, followed by weekly injections. Interestingly, safranin-O staining and Osteoarthritis Research Society International (OARSI) scoring revealed that Cramp-treated mice had more severe cartilage destruction and synovial inflammation than vehicle-treated mice. Although not statistically significant, meniscus ossification appeared to be slightly increased in Cramp-treated mice. Taken together with our in vitro data, these results suggest that Cramp promotes OA.

\subsection{Introduction of Excessive Cramp Causes Meniscus Ossification and Tears}

We next investigated whether high concentrations of Cramp could lead to changes in the joint architecture. As shown in Figure 6A, mice were treated with $10 \mu \mathrm{L}$ of $10 \mathrm{mM}$ control HP (2-20) peptide, $1 \mathrm{mM}$ Cramp, or $10 \mathrm{mM}$ Cramp once weekly for two weeks. 
Histological evaluation was conducted with joint sections of mice collected three weeks after the first IA injection. Whereas the control $10 \mathrm{mM} \mathrm{HP}$ (2-20) peptide showed no visible effects on joint homeostasis, $1 \mathrm{mM}$ Cramp caused mild to moderate ossification in the anterior location of the menisci and medial meniscus (Figure 6A). Measurement of the ossified region indicated a significant increase in the ossification of the anterior meniscal horn by $1 \mathrm{mM}$ Cramp treatment (Figure 6B). Interestingly, excessive Cramp at $10 \mathrm{mM}$ resulted in a large amount of ossification of the meniscus (Figure 6A,B). While cartilage destruction was not obvious at three weeks after Cramp treatment, Cramp dosedependently increased synovial inflammation. These results indicate that Cramp causes pathological changes in the meniscus and synovium at the early period.

A
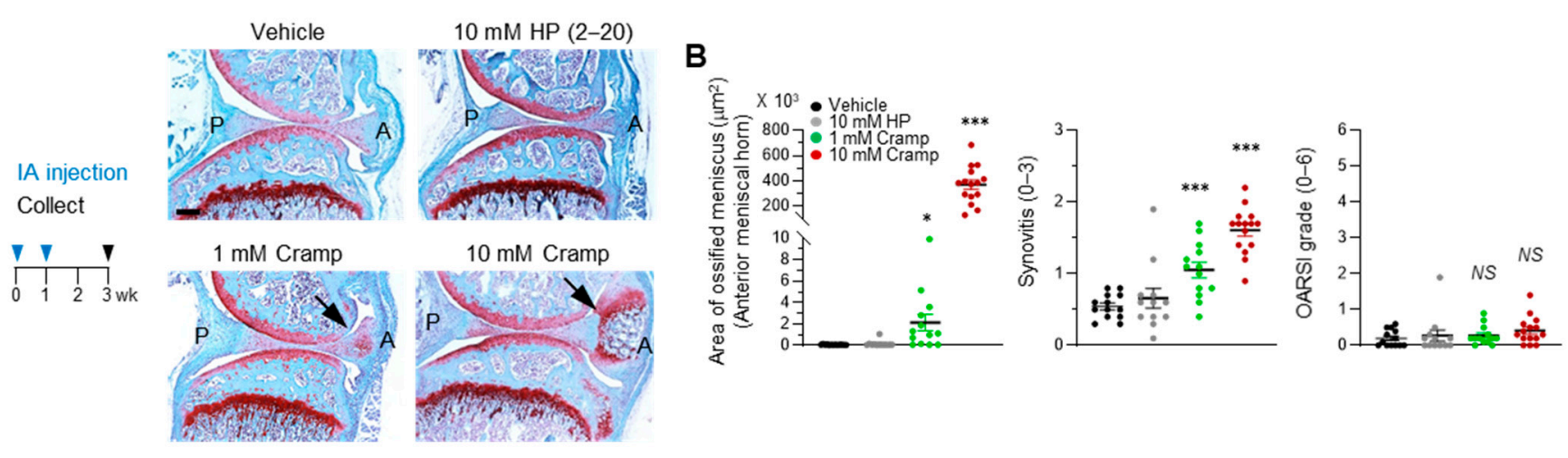

C
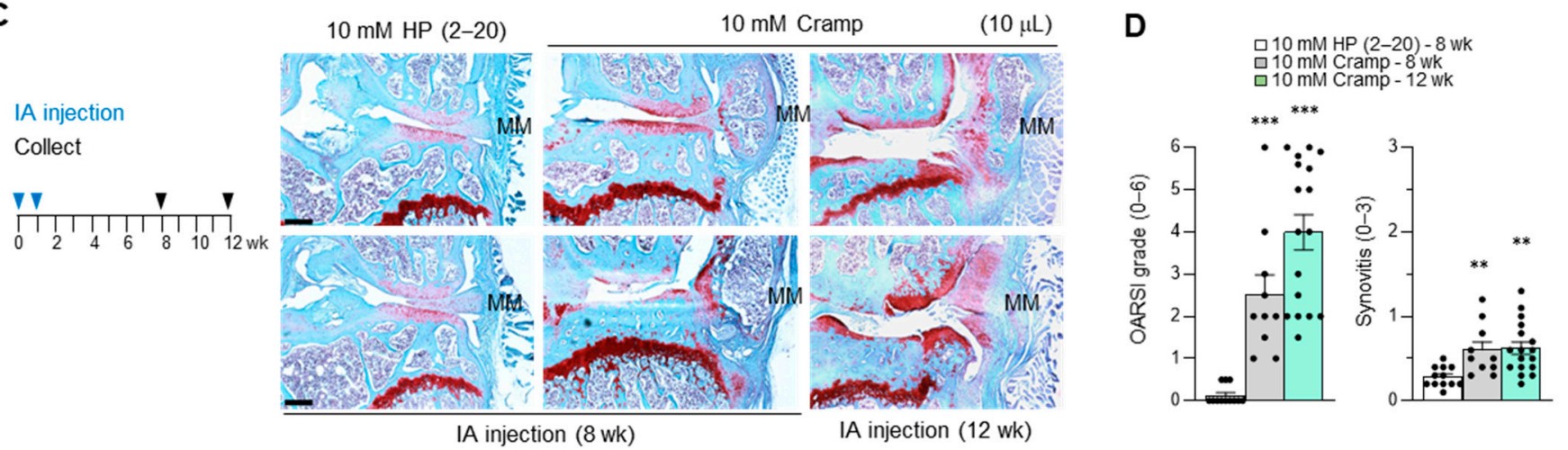

Figure 6. IA injection of Cramp at high concentrations results in ossification and tear of the meniscus and cartilage destruction. (A,B) 12-week-old male mice were subjected to IA injection with $10 \mu \mathrm{L}$ of vehicle $(n=13), 10 \mathrm{mM}$ control HP (2-20) peptide $(n=12), 1 \mathrm{mM}$ Cramp $(n=13)$ or $10 \mathrm{mM}$ Cramp $(n=15)$ for 3 weeks. (A) Safranin-O staining of cartilage sections. Arrows indicate the region of meniscal ossification. P, posterior meniscal horn; A, anterior meniscal horn. Bars $=200 \mu \mathrm{m}$. (B) Measurement of ossified region in anterior meniscal horn or scoring of synovitis and OARSI grade. Values are the means \pm SEM. ${ }^{*} p<0.05,{ }^{* * *} p<0.001$ versus vehicle-treated group. NS, not significant. (C,D) 12-week-old male mice were treated with $10 \mu \mathrm{L}$ of $10 \mathrm{mM}$ control HP (2-20) peptide or Cramp. Mice were harvested at 8 or 12 weeks after first IA injection. Representative images of safranin-O staining (C) and scoring of OARSI grade and synovitis (D) are shown. $\mathrm{MM}$, medial meniscus. Bars $=200 \mu \mathrm{m}$. Values are the means \pm SEM. $n=12$ for $10 \mathrm{mM} \mathrm{HP}(2-20) 8 \mathrm{wk}, n=10$ for $10 \mathrm{mM}$ Cramp $8 \mathrm{wk}$ and $n=17$ for $10 \mathrm{mM}$ Cramp 12wk. ${ }^{* *} p<0.01,{ }^{* * *} p<0.001$ versus control HP (2-20) peptide-treated group.

Meniscus modifications, including ossification, have been reported in both spontaneous and traumatic OA $[20,21,48]$. We hypothesized that meniscal ossification induced by Cramp could change the joint biomechanics and cartilage destruction. Therefore, we examined the long-term effects of $10 \mathrm{mM}$ Cramp on joint destruction. At 8 weeks, a large amount of ossification or breakdown of the medial meniscus and subsequent cartilage destruction were observed with elevated synovitis (Figure 6C,D). At 12 weeks, most joints showed meniscal tears with cartilage destruction. Thus, meniscal ossification and tears caused by Cramp influenced joint stability and thereby caused cartilage destruction. Collectively, 
these data indicate that Cramp is involved in various skeletal pathophysiologies, including chondrocyte catabolism in articular cartilage, inflammation in the synovial membrane and bone development in the meniscus.

\section{Discussion}

Increasing evidence has demonstrated that cathelicidins play a critical role not only in infectious diseases but also in controlling many types of tissue diseases. Although previous studies identified the up-regulation of LL-37 in OA synovial membranes [40], its biological effect was unknown. In this study, we examined the functional role of cathelicidin in murine OA pathogenesis and found that Cramp has disease-promoting roles in OA development by regulating chondrocyte catabolism, synovial inflammation and meniscus damage.

We initially observed a high level of Cramp in OA cartilage, suggesting that this AMP might participate in OA pathogenesis. The hypothesis was also based on studies of another AMP, HBD-3. Up-regulation of HBD-3 along with Cramp was found in the synovial membrane of patients with OA [40]. A subsequent study showed that HBD-3 is not only up-regulated in the cartilage of OA patients, but also stimulates the expression of catabolic MMPs in chondrocytes [49]. As these HBD-3 results were very similar to our findings in this study, we speculate that AMPs function as general factors for OA development, possibly by acting through cooperative mechanisms.

We found a significant increase in Cramp expression in traumatic OA cartilage and chondrocyte culture. The chondrocyte catabolism stimulated by Cramp treatment suggests that Cramp is associated with ECM degradation in the articular cartilage. Moreover, Cramp was found to be required for IL-1 $\beta$-induced expression of matrix-degrading enzymes, including Mmp13 and Adamts5 (Figure 4A). As the genetic ablation of either Mmp13 or AdamtS5 prevents OA cartilage destruction [47,50], our findings support the causative role of Cramp in cartilage catabolism. However, studies are needed to determine whether Cramp-deficient mice also exhibit alleviation of OA development and how Cramp activates catabolic factor expression. Thus, the effects of Cramp should be confirmed using knockout mice and the associated signaling pathways should be defined to target OA development.

In histological analysis, the internalization of exogenous Cramp was monitored in mouse knee joints by IHC staining, and was detected in the synovium, cartilage, and meniscus even at $24 \mathrm{~h}$ after IA injection (Figure 5A). Due to the antibody sensitivity or Cramp half-life during the treatment period, it was difficult to determine how much Cramp was delivered into each joint component. Nevertheless, Cramp appeared to associate with cells in the synovial membrane, cartilage, and meniscus. Several receptors, including FPR2, P2 $\times 7$, and CXCR2, have been proposed to interact with cathelicidins [28,29]. In addition, ECM- or caveolae-mediated mechanisms have been reported in the regulation of cathelicidin transportation $[31,51,52]$. Although the precise mechanisms need to be investigated, Cramp may be involved in catabolic signaling in the joint tissues through interactions with the above signaling mediators.

Meniscus degeneration and tears are key features of OA disease [53]. As studies of such soft tissue changes are considered to be important for understanding OA disease, the identification of factors that regulate meniscus homeostasis or degeneration can provide clues for developing strategies for treating OA disease. In this study, we evaluated the meniscus-disrupting factor Cramp. Our results demonstrated that ectopic introduction of approximately $40 \mu \mathrm{g}$ of Cramp (10 $\mu \mathrm{L}$ of $1 \mathrm{mM}$ Cramp) into mouse knee joints visibly increased meniscus ossification (Figure 6B). Furthermore, dose-dependent development of meniscus ossification and cartilage destruction were observed when very high and potentially artificial concentrations of Cramp ( $10 \mu \mathrm{L}$ of $10 \mathrm{mM}$ Cramp) were IA-injected. As the most notable change in the early period of Cramp-treated joints was an increase in meniscus ossification, the cartilage destruction observed might be due to abnormal bone formation in the meniscus followed by meniscus breakdown. Interestingly, recent studies identified several transcription factors, such as Foxo1, Foxo3, and Mohawk, which are critical for the maintenance of meniscus homeostasis and for reducing OA severity $[54,55]$. In fact, the 
genetic inhibition of Foxo1/3 resulted in increased meniscal ossification. Whether Cramp participates in functional cross-talk with the transcription factors in meniscus biology needs to be determined in further studies. It would also be interesting to investigate whether endogenous and exogenous Cramp promote osteogenesis in vitro.

\section{Materials and Methods}

\subsection{Chondrocyte Culture, Peptide Treatment, and siRNA Transfection}

Mouse primary chondrocytes were isolated from the femoral condyles and tibial plateaus of 5-day-old mice by digestion with $0.2 \%$ collagenase (Sigma, St. Louis, MO, USA; C6885) as described previously [15]. Chondrocytes $\left(5-6 \times 10^{5}\right)$ were seeded into 6-well plates in Dulbecco's Modified Eagle's Medium containing 10\% fetal bovine serum and antibiotics. The next day, the cells were serum-starved overnight, and then treated with each peptide for $24 \mathrm{~h}$ at the concentrations indicated in each figure legend. All peptides were synthesized by Anygen Inc. (Gwangju, Korea). The amino acid sequences of the four peptides were as follows: Cramp, GLLRKGGEKIGEKLKKIGQKIKNFFQKLVPQPEQ; LL-37, LLGDFFRKSKEKIGKEFKRIVQRIKDFLRNLVPRTES; HP (2-20), AKKVFKRLEKLFSKIQNDK; HP-MA, AKKVFKRLGIGKFLHSAKKF. IL-1 $\beta$ (GenScript, Piscataway, NJ, USA; Z02922), TNF- $\alpha$ (EMD Millipore, Temecula, CA, USA; GF027), and SC514 (Tocris Bioscience; 3318) were also used for cell experiments at the concentrations and periods indicated in the figure legends.

For KD analysis of Cramp, the cells were treated with hyaluronidase for $2 \mathrm{~h}$ in serum-free medium, and then transfected with either $10 \mathrm{nM}$ of control or Cramp siRNA (Ambion, Austin, TX, USA) using Lipofectamine RNAiMAX (Invitrogen, Carlsbad, CA, USA; 13778150). Chondrocytes were harvested at $36 \mathrm{~h}$ after treatment with IL-1 $\beta$.

\subsection{RNA Analysis}

Total RNA was extracted from the cells using TRI reagent (Molecular Research Center, Cincinnati, OH, USA). RNA was reverse-transcribed using oligo dT primer and reverse transcriptase (Promega, Madison, WI, USA; A3800) according to the manufacturer's instructions. Quantitative PCR was performed using qPCR 2X PreMIX SYBR (Enzynomics, Daejeon, Korea; RT500) on a 7500 Real Time PCR System (Applied Biosystems, Foster City, CA, USA). Data were calculated using the $2^{-\Delta \Delta C t}$ method. The values were normalized to $\beta$-actin levels. Primers were synthesized according to our previous report [15]. The Cramp primer sequences used were as follows: $5^{\prime}$-CTACCTGAGCAATGTGCCTTC- $3^{\prime}$ and 5-CAGGCCTACTACTCTGGCTGA-3'.

\subsection{Western Blot Analysis}

Whole cell lysates were extracted in lysis buffer $(50 \mathrm{mM}$ Tris $\mathrm{HCl}, \mathrm{pH}$ 7.4, $150 \mathrm{mM}$ $\mathrm{NaCl}, 1 \mathrm{mM}$ EDTA, $1 \% \mathrm{NP}-40,0.5 \%$ sodium deoxycholate) containing cocktails of protease and phosphatase inhibitors (Thermo Fisher Scientific, Waltham, MA, USA; 78444). Protein concentrations were determined by BCA assay (Sigma, St. Louis, MO, USA). Culture supernatants were also collected to determine the levels of extracellular Mmp3 and Mmp13. The lysates or supernatants were resolved by SDS-PAGE, transferred onto nitrocellulose membranes, and incubated with antibodies against Cramp (1:1000; Abcam, Cambridge, UK; ab93357), Mmp3 (1:10,000; Abcam; ab52915), Mmp13 (1:500; Aviva Systems Biology, San Diego, CA, USA; ARP56350_P050), Sox9 (1:1000; Abcam; ab185966), or $\beta$-actin (1:10,000; Abcam; ab8226).

\subsection{IA Injection in Mice, and Experimental $O A$}

Twelve-week-old male mice on the C57BL/ 6 background were used for animal experiments. For IA injection of the peptide into the mouse knee joint, the mice were anesthetized and injected with $10 \mu \mathrm{L}$ of each peptide. The experimental design of IA injection with peptide concentration and injection period is shown in each figure. For the experimental OA study, DMM surgery was performed as described previously [56]. Seven days 
after DMM surgery, the vehicle or Cramp peptide (10 $\mu \mathrm{L}$ of $25 \mu \mathrm{M}$; approximately $1 \mu \mathrm{g})$ was first injected into mice by IA injection, and then injected weekly a total of seven times before the mice were sacrificed at 9 weeks for histological analysis. The mice were housed in the animal facility of Chosun University. All mouse procedures were approved by the Chosun University Institutional Animal Care and Use Committee (approval no. CIACUC2017-A0046).

\subsection{Histology and Immunohistochemistry}

To prepare paraffin blocks, the knee joints of mice were fixed in $4 \%$ paraformaldehyde for $24 \mathrm{~h}$, decalcified in $0.5 \mathrm{M}$ EDTA for 2-3 weeks, and embedded in paraffin. Blocks were sectioned at a thickness of $7 \mu \mathrm{M}$. Serial sections were obtained from the whole joint tissue, and 3-5 sections per mouse were stained with safranin-O as described previously [15]. Cartilage degeneration was scored by three observers blinded to the sample information using the OARSI grading system [57]. Synovitis and osteophyte maturity were scored as described previously [15]. The degree of meniscus ossification was determined by measuring the ossified area in the anterior meniscal horn using ImageJ software (NIH, Bethesda, MD, USA). For immunohistochemical staining of Cramp, antigen retrieval was conducted by incubating the sections with trypsin (Abcam; ab970) for $30 \mathrm{~min}$. After blocking with $10 \%$ normal goat serum (Thermo Fisher Scientific; 50062Z), the sections were incubated with the Cramp antibody (Innovagen AB, Lund, Sweden; PA-CRPL-100) at $4{ }^{\circ} \mathrm{C}$ overnight. Using an IHC staining kit (GBI Labs, Bothell, WA, USA; D06), the sections were incubated with secondary antibody followed by incubation with chromogen AEC according to the manufacturer's instructions. Cramp levels were measured using ImageJ software.

\subsection{Statistical Analysis}

All data collected in this study were analyzed statistically by Student's two-tailed $t$-test using the Microsoft Office 365 Excel application. The number of independent experiments (cell experiments) or mice is indicated by $n$. The results were considered to be significant when $p<0.05$.

\section{Conclusions}

In this study, we explored whether Cramp regulates OA pathogenesis. We found that Cramp, an up-regulated peptide in OA disease, promotes chondrocyte catabolic functions. We further showed that the administration of Cramp into mouse knee joints accelerates experimental OA progression and meniscal damage. Overall, our findings suggest that Cramp plays a role in OA disease.

Author Contributions: Conceptualization, M.-C.C. and Y.P.; formal analysis, M.-C.C., J.J., M.L. and J.P.; investigation, M.-C.C. and J.J.; data curation, M.-C.C., J.J., M.L. and J.P.; writing-original draft preparation, M.-C.C.; writing-review and editing, M.-C.C., J.J. and Y.P.; supervision, Y.P.; funding acquisition, M.-C.C. and Y.P. All authors have read and agreed to the published version of the manuscript.

Funding: This research was supported by the National Research Foundation of Korea (NRF) grants funded by the Korean Government (No. 2018R1D1A1A02042725, 2021R1A2C1003561, 2019R1A2B5B03070330, 2017M3A9E4077206).

Institutional Review Board Statement: All mouse procedures were approved by the Chosun University Institutional Animal Care and Use Committee (CIACUC) (protocol code CIACUC2017-A0046 and date of approval, 3 January 2018).

Informed Consent Statement: Not applicable.

Data Availability Statement: The data will be available from the corresponding author upon reasonable request.

Conflicts of Interest: The authors declare no conflict of interest. 


\section{References}

1. Loeser, R.F.; Goldring, S.R.; Scanzello, C.R.; Goldring, M.B. Osteoarthritis: A disease of the joint as an organ. Arthritis Rheum. 2012, 64, 1697-1707. [CrossRef]

2. Goldring, M.B.; Goldring, S.R. Osteoarthritis. J. Cell. Physiol. 2007, 213, 626-634. [CrossRef]

3. Englund, M.; Roos, E.M.; Lohmander, L.S. Impact of type of meniscal tear on radiographic and symptomatic knee osteoarthritis: A sixteen-year followup of meniscectomy with matched controls. Arthritis Rheum. 2003, 48, 2178-2187. [CrossRef] [PubMed]

4. Englund, M.; Felson, D.T.; Guermazi, A.; Roemer, F.W.; Wang, K.; Crema, M.D.; Lynch, J.A.; Sharma, L.; Segal, N.A.; Lewis, C.E.; et al. Risk factors for medial meniscal pathology on knee MRI in older US adults: A multicentre prospective cohort study. Ann. Rheum. Dis. 2011, 70, 1733-1739. [CrossRef]

5. $\quad$ Englund, M.; Guermazi, A.; Gale, D.; Hunter, D.J.; Aliabadi, P.; Clancy, M.; Felson, D.T. Incidental meniscal findings on knee MRI in middle-aged and elderly persons. N. Engl. J. Med. 2008, 359, 1108-1115. [CrossRef] [PubMed]

6. Heinegard, D.; Saxne, T. The role of the cartilage matrix in osteoarthritis. Nat. Rev. Rheumatol. 2011, 7, 50-56. [CrossRef] [PubMed]

7. Hashimoto, M.; Nakasa, T.; Hikata, T.; Asahara, H. Molecular network of cartilage homeostasis and osteoarthritis. Med. Res. Rev. 2008, 28, 464-481. [CrossRef]

8. Goldring, M.B.; Marcu, K.B. Cartilage homeostasis in health and rheumatic diseases. Arthritis Res. 2009, 11, 224. [CrossRef]

9. Hwang, H.S.; Kim, H.A. Chondrocyte Apoptosis in the Pathogenesis of Osteoarthritis. Int. J. Mol. Sci. 2015, 16, 26035-26054. [CrossRef] [PubMed]

10. Zeng, N.; Yan, Z.P.; Chen, X.Y.; Ni, G.X. Infrapatellar Fat Pad and Knee Osteoarthritis. Aging Dis. 2020, 11, 1317-1328. [CrossRef]

11. Kapoor, M.; Martel-Pelletier, J.; Lajeunesse, D.; Pelletier, J.P.; Fahmi, H. Role of proinflammatory cytokines in the pathophysiology of osteoarthritis. Nat. Rev. Rheumatol. 2011, 7, 33-42. [CrossRef]

12. Little, C.B.; Hunter, D.J. Post-traumatic osteoarthritis: From mouse models to clinical trials. Nat. Rev. Rheumatol. 2013, 9, 485-497. [CrossRef]

13. Troeberg, L.; Nagase, H. Proteases involved in cartilage matrix degradation in osteoarthritis. Biochim. Biophys. Acta 2012, 1824, 133-145. [CrossRef] [PubMed]

14. Choi, M.C.; Jo, J.; Park, J.; Kang, H.K.; Park, Y. NF-kappaB Signaling Pathways in Osteoarthritic Cartilage Destruction. Cells 2019, 8, 734. [CrossRef] [PubMed]

15. Choi, M.C.; MaruYama, T.; Chun, C.H.; Park, Y. Alleviation of Murine Osteoarthritis by Cartilage-Specific Deletion of IkappaBzeta. Arthritis Rheumatol. 2018, 70, 1440-1449. [CrossRef]

16. Kobayashi, H.; Chang, S.H.; Mori, D.; Itoh, S.; Hirata, M.; Hosaka, Y.; Taniguchi, Y.; Okada, K.; Mori, Y.; Yano, F.; et al. Biphasic regulation of chondrocytes by Rela through induction of anti-apoptotic and catabolic target genes. Nat. Commun. 2016, 7, 13336. [CrossRef] [PubMed]

17. Glasson, S.S.; Blanchet, T.J.; Morris, E.A. The surgical destabilization of the medial meniscus (DMM) model of osteoarthritis in the 129/SvEv mouse. Osteoarthr. Cartil. 2007, 15, 1061-1069. [CrossRef] [PubMed]

18. Xie, J.; Zhang, D.; Lin, Y.; Yuan, Q.; Zhou, X. Anterior Cruciate Ligament Transection-Induced Cellular and Extracellular Events in Menisci: Implications for Osteoarthritis. Am. J. Sports Med. 2018, 46, 1185-1198. [CrossRef]

19. Gamer, L.W.; Xiang, L.; Rosen, V. Formation and maturation of the murine meniscus. J. Orthop. Res. 2017, 35, 1683-1689. [CrossRef]

20. Ramos-Mucci, L.; Javaheri, B.; van't Hof, R.; Bou-Gharios, G.; Pitsillides, A.A.; Comerford, E.; Poulet, B. Meniscal and ligament modifications in spontaneous and post-traumatic mouse models of osteoarthritis. Arthritis Res. 2020, 22, 171. [CrossRef]

21. Kapadia, R.D.; Badger, A.M.; Levin, J.M.; Swift, B.; Bhattacharyya, A.; Dodds, R.A.; Coatney, R.W.; Lark, M.W. Meniscal ossification in spontaneous osteoarthritis in the guinea-pig. Osteoarthr. Cartil. 2000, 8, 374-377. [CrossRef] [PubMed]

22. Thomsen, J.S.; Straarup, T.S.; Danielsen, C.C.; Oxlund, H.; Bruel, A. Relationship between articular cartilage damage and subchondral bone properties and meniscal ossification in the Dunkin Hartley guinea pig model of osteoarthritis. Scand. J. Rheumatol. 2011, 40, 391-399. [CrossRef]

23. Cheung, H.S.; Sallis, J.D.; Demadis, K.D.; Wierzbicki, A. Phosphocitrate blocks calcification-induced articular joint degeneration in a guinea pig model. Arthritis Rheum. 2006, 54, 2452-2461. [CrossRef] [PubMed]

24. Jorgensen, B.; Jensen, H.E. Periarticular ossification at the elbow joint and meniscal ossification in the stifle joint of pigsOccurrence, pathomorphology, breed differences and correlations with osteochondrosis, leg weakness and production parameters. J. Vet. Med. A Physiol. Pathol. Clin. Med. 2002, 49, 353-357. [CrossRef] [PubMed]

25. Weber, N.A. Apparent primary ossification of the menisci in a dog. J. Am. Vet. Med. Assoc. 1998, 212, $1892-1894$.

26. Prasad, S.V.; Fiedoruk, K.; Daniluk, T.; Piktel, E.; Bucki, R. Expression and Function of Host Defense Peptides at Inflammation Sites. Int. J. Mol. Sci. 2019, 21, 104. [CrossRef]

27. Gupta, S.; Bhatia, G.; Sharma, A.; Saxena, S. Host defense peptides: An insight into the antimicrobial world. J. Oral Maxillofac. Pathol. 2018, 22, 239-244. [CrossRef]

28. Alford, M.A.; Baquir, B.; Santana, F.L.; Haney, E.F.; Hancock, R.E.W. Cathelicidin Host Defense Peptides and Inflammatory Signaling: Striking a Balance. Front. Microbiol. 2020, 11, 1902. [CrossRef]

29. Vandamme, D.; Landuyt, B.; Luyten, W.; Schoofs, L. A comprehensive summary of LL-37, the factotum human cathelicidin peptide. Cell Immunol. 2012, 280, 22-35. [CrossRef] 
30. Pircher, J.; Czermak, T.; Ehrlich, A.; Eberle, C.; Gaitzsch, E.; Margraf, A.; Grommes, J.; Saha, P.; Titova, A.; Ishikawa-Ankerhold, H.; et al. Cathelicidins prime platelets to mediate arterial thrombosis and tissue inflammation. Nat. Commun. 2018, 9, 1523. [CrossRef]

31. Doring, Y.; Drechsler, M.; Wantha, S.; Kemmerich, K.; Lievens, D.; Vijayan, S.; Gallo, R.L.; Weber, C.; Soehnlein, O. Lack of neutrophil-derived CRAMP reduces atherosclerosis in mice. Circ. Res. 2012, 110, 1052-1056. [CrossRef]

32. Zhang, L.J.; Guerrero-Juarez, C.F.; Hata, T.; Bapat, S.P.; Ramos, R.; Plikus, M.V.; Gallo, R.L. Innate immunity. Dermal adipocytes protect against invasive Staphylococcus aureus skin infection. Science 2015, 347, 67-71. [CrossRef] [PubMed]

33. Edfeldt, K.; Agerberth, B.; Rottenberg, M.E.; Gudmundsson, G.H.; Wang, X.B.; Mandal, K.; Xu, Q.; Yan, Z.Q. Involvement of the antimicrobial peptide LL-37 in human atherosclerosis. Arterioscler. Thromb. Vasc. Biol. 2006, 26, 1551-1557. [CrossRef] [PubMed]

34. Chen, K.; Yoshimura, T.; Yao, X.; Gong, W.; Huang, J.; Dzutsev, A.K.; McCulloch, J.; O’HUigin, C.; Bian, X.W.; Trinchieri, G.; et al Distinct contributions of cathelin-related antimicrobial peptide (CRAMP) derived from epithelial cells and macrophages to colon mucosal homeostasis. J. Pathol. 2020, 253, 339-350. [CrossRef] [PubMed]

35. Kuroda, K.; Okumura, K.; Isogai, H.; Isogai, E. The Human Cathelicidin Antimicrobial Peptide LL-37 and Mimics are Potential Anticancer Drugs. Front. Oncol. 2015, 5, 144. [CrossRef]

36. Pan, L.L.; Liang, W.; Ren, Z.; Li, C.; Chen, Y.; Niu, W.; Fang, X.; Liu, Y.; Zhang, M.; Diana, J.; et al. Cathelicidin-related antimicrobial peptide protects against ischaemia reperfusion-induced acute kidney injury in mice. Br. J. Pharm. 2020, 177, 2726-2742. [CrossRef]

37. Wu, Y.; Zhang, Y.; Zhang, J.; Zhai, T.; Hu, J.; Luo, H.; Zhou, H.; Zhang, Q.; Zhou, Z.; Liu, F. Cathelicidin aggravates myocardial ischemia/reperfusion injury via activating TLR4 signaling and P2X7R/NLRP3 inflammasome. J. Mol. Cell. Cardiol. 2020, 139, 75-86. [CrossRef] [PubMed]

38. Zhou, Q.; Pan, L.L.; Xue, R.; Ni, G.; Duan, Y.; Bai, Y.; Shi, C.; Ren, Z.; Wu, C.; Li, G.; et al. The anti-microbial peptide LL-37/CRAMP levels are associated with acute heart failure and can attenuate cardiac dysfunction in multiple preclinical models of heart failure. Theranostics 2020, 10, 6167-6181. [CrossRef] [PubMed]

39. Wertenbruch, S.; Drescher, H.; Grossarth, V.; Kroy, D.; Giebeler, A.; Erschfeld, S.; Heinrichs, D.; Soehnlein, O.; Trautwein, C.; Brandenburg, L.O.; et al. The Anti-Microbial Peptide LL-37/CRAMP Is Elevated in Patients with Liver Diseases and Acts as a Protective Factor during Mouse Liver Injury. Digestion 2015, 91, 307-317. [CrossRef]

40. Paulsen, F.; Pufe, T.; Conradi, L.; Varoga, D.; Tsokos, M.; Papendieck, J.; Petersen, W. Antimicrobial peptides are expressed and produced in healthy and inflamed human synovial membranes. J. Pathol. 2002, 198, 369-377. [CrossRef]

41. Hoffmann, M.H.; Bruns, H.; Backdahl, L.; Neregard, P.; Niederreiter, B.; Herrmann, M.; Catrina, A.I.; Agerberth, B.; Holmdahl, R. The cathelicidins LL-37 and rCRAMP are associated with pathogenic events of arthritis in humans and rats. Ann. Rheum. Dis. 2013, 72, 1239-1248. [CrossRef]

42. Schmidt, N.; Art, J.; Forsch, I.; Werner, A.; Erkel, G.; Jung, M.; Horke, S.; Kleinert, H.; Pautz, A. The anti-inflammatory fungal compound (S)-curvularin reduces proinflammatory gene expression in an in vivo model of rheumatoid arthritis. J. Pharm. Exp. 2012, 343, 106-114. [CrossRef] [PubMed]

43. Kahlenberg, J.M.; Kaplan, M.J. Little peptide, big effects: The role of LL-37 in inflammation and autoimmune disease. J. Immunol. 2013, 191, 4895-4901. [CrossRef] [PubMed]

44. Kishore, N.; Sommers, C.; Mathialagan, S.; Guzova, J.; Yao, M.; Hauser, S.; Huynh, K.; Bonar, S.; Mielke, C.; Albee, L.; et al. A selective IKK-2 inhibitor blocks NF-kappa B-dependent gene expression in interleukin-1 beta-stimulated synovial fibroblasts. J. Biol. Chem. 2003, 278, 32861-32871. [CrossRef] [PubMed]

45. Bylund, J.; Christophe, T.; Boulay, F.; Nystrom, T.; Karlsson, A.; Dahlgren, C. Proinflammatory activity of a cecropin-like antibacterial peptide from Helicobacter pylori. Antimicrob. Agents Chemother. 2001, 45, 1700-1704. [CrossRef]

46. Park, Y.; Lee, D.G.; Hahm, K.S. HP(2-9)-magainin 2(1-12), a synthetic hybrid peptide, exerts its antifungal effect on Candida albicans by damaging the plasma membrane. J. Pept. Sci. 2004, 10, 204-209. [CrossRef] [PubMed]

47. Little, C.B.; Barai, A.; Burkhardt, D.; Smith, S.M.; Fosang, A.J.; Werb, Z.; Shah, M.; Thompson, E.W. Matrix metalloproteinase 13-deficient mice are resistant to osteoarthritic cartilage erosion but not chondrocyte hypertrophy or osteophyte development. Arthritis Rheum. 2009, 60, 3723-3733. [CrossRef]

48. Kwok, J.; Onuma, H.; Olmer, M.; Lotz, M.K.; Grogan, S.P.; D’Lima, D.D. Histopathological analyses of murine menisci: Implications for joint aging and osteoarthritis. Osteoarthr. Cartil. 2016, 24, 709-718. [CrossRef]

49. Varoga, D.; Pufe, T.; Harder, J.; Schroder, J.M.; Mentlein, R.; Meyer-Hoffert, U.; Goldring, M.B.; Tillmann, B.; Hassenpflug, J.; Paulsen, F. Human beta-defensin 3 mediates tissue remodeling processes in articular cartilage by increasing levels of metalloproteinases and reducing levels of their endogenous inhibitors. Arthritis Rheum. 2005, 52, 1736-1745. [CrossRef]

50. Glasson, S.S.; Askew, R.; Sheppard, B.; Carito, B.; Blanchet, T.; Ma, H.L.; Flannery, C.R.; Peluso, D.; Kanki, K.; Yang, Z.; et al. Deletion of active ADAMTS5 prevents cartilage degradation in a murine model of osteoarthritis. Nature 2005, 434, 644-648. [CrossRef]

51. Wantha, S.; Alard, J.E.; Megens, R.T.; van der Does, A.M.; Doring, Y.; Drechsler, M.; Pham, C.T.; Wang, M.W.; Wang, J.M.; Gallo, R.L.; et al. Neutrophil-derived cathelicidin promotes adhesion of classical monocytes. Circ. Res. 2013, 112, 792-801. [CrossRef] [PubMed]

52. Soehnlein, O.; Wantha, S.; Simsekyilmaz, S.; Doring, Y.; Megens, R.T.; Mause, S.F.; Drechsler, M.; Smeets, R.; Weinandy, S.; Schreiber, F.; et al. Neutrophil-derived cathelicidin protects from neointimal hyperplasia. Sci. Transl. Med. 2011, 3, 103-198. [CrossRef] [PubMed] 
53. Bennett, L.D.; Buckland-Wright, J.C. Meniscal and articular cartilage changes in knee osteoarthritis: A cross-sectional doublecontrast macroradiographic study. Rheumatology 2002, 41, 917-923. [CrossRef] [PubMed]

54. Lee, K.I.; Gamini, R.; Olmer, M.; Ikuta, Y.; Hasei, J.; Baek, J.; Alvarez-Garcia, O.; Grogan, S.P.; D'Lima, D.D.; Asahara, H.; et al Mohawk is a transcription factor that promotes meniscus cell phenotype and tissue repair and reduces osteoarthritis severity. Sci. Transl. Med. 2020, 12. [CrossRef] [PubMed]

55. Lee, K.I.; Choi, S.; Matsuzaki, T.; Alvarez-Garcia, O.; Olmer, M.; Grogan, S.P.; D'Lima, D.D.; Lotz, M.K. FOXO1 and FOXO3 transcription factors have unique functions in meniscus development and homeostasis during aging and osteoarthritis. Proc. Natl. Acad. Sci. USA 2020, 117, 3135-3143. [CrossRef]

56. Choi, M.C.; Choi, W.H. Mithramycin A Alleviates Osteoarthritic Cartilage Destruction by Inhibiting HIF-2alpha Expression. Int. J. Mol. Sci. 2018, 19, 1411. [CrossRef]

57. Glasson, S.S.; Chambers, M.G.; Van Den Berg, W.B.; Little, C.B. The OARSI histopathology initiative-Recommendations for histological assessments of osteoarthritis in the mouse. Osteoarthr. Cartil. 2010, 18, 17-23. [CrossRef] [PubMed] 